\title{
Reserch on implementing education for sustainable development
}

\author{
Alina-Mihaela DIMA \\ The Bucharest University of Economic Studies, Faculty of Business Administration \\ alina.dima@fabiz.ase.ro
}

\section{Georgeta-Madalina MEGHISAN-TOMA}

The Bucharest University of Economic Studies, Faculty of Business Administration, Bucharest; Romanian Academy, National Institute for Economic Research "Costin C. Kiritescu”, Bucharest madalina_meghisan@yahoo.com

\begin{abstract}
The current research aims to identify the main directions to implement sustainability in education through curriculum; interdisciplinary/ transdiciplinary approach; business environment; entrepreneurship and innovation. In order to fulfil the objectives of the current study, a questionnairebased survey was sent by email to UNESCO Chairs from Balkan Region and the responses were analysed using descriptive statistics and factor analysis. According to the results, UNESCO chairs are working towards the main goals for higher education in the EU through some instruments: Establishing the main directions for a quality education; Establishing the relevant directions towards the implementation of sustainability in education through curriculum; Establishing the relevant directions towards the implementation of sustainability in education by an interdisciplinary/ transdisciplinary approach; Establishing the relevant directions towards the implementation of sustainability in education in collaboration with the business environment; Establishing the main directions in the field of education for entrepreneurship and innovation.
\end{abstract}

Keywords: education, sustainable development, curriculum, interdisciplinary/ transdiciplinary approach, business environment, entrepreneurship, innovation.

\section{Introduction}

Education for Sustainable Development (ESD) is considered a primary goal for UNESCO starting from 1992 (UNESCO's 'Agenda 21') supported continuously by United Nations (the plan 'Educating for Sustainable Future: Environment Population and Development in 1992). Later on, in 2002, UNESCO established the UN Decade (2005-2014) of Education for Sustainable Development (DESD) (Wu \& Shen, 2016). The recent Global Action Programme (GAP) on ESD endorsed by UNESCO in 2013 and the 2030 Agenda for Sustainable Development adopted by United Nations in 2015 reflects the framework for importance of the education goal and its major impact on society within the last century. Education is considered by UN a primary element - Sustainable Development Goal 4 - along with other relevant indicators within the Sustainable Development Goals (SDGs). Global issues - such as climate change or poverty reduction, clean energy or quality of life - require a dramatic change in our life and a transformation of the mentality and action directions. Education is regarded as a means through which individuals can improve their quality of life, while also contributing to the development of societies (Paunescu et al, 2017). To achieve this major change, we need new skills, values and attitudes that lead to more sustainable societies. The key to implement sustainability is closely linked to the Curriculum and the Interdisciplinary approach to education. Education systems should respond to these pressures by defining 
key learning objectives, introducing teaching methods centered on learners, and asking their institutions to include sustainability principles in their management structures (UNESCO, 2017). Universities are expected to play an important role as a change agent to feed community development through inter-generational learning (Bratianu, 2010; Bratianu and Bolisani, 2015; Lefter et al., 2011), to develop their own way of sustainable growth by creating knowledge, skills and jobs (Paunescu et al, 2017) and to help society to achieve a more sustainable future (Chalkley, 2006). Moreover, the business climate of a country has an important relevance (Buse at al., 2007) and is "widely used in various analyses, both scientific and practical" (Dascalu et al., 2016), together with the financial sector, considered to have "a great importance for supporting economic growth" (Cristea et al. 2010).

\section{Literature review}

All educational sectors within a society have to implement "the programs of education for sustainable development or sustainability education" (UNESCO, 2009). Thus, efforts were made to "rethink and revise educational programs towards sustainability, which are important for present and future communities" (Faham et al., 2016). Several authors emphasized the necessity to "integrate programs of education for sustainable development into higher education" (Figuerio and Raufflet, 2015; Brundiers et al., 2010; Bryce et al., 2004).

However, "the education for sustainable development can change individual action and behavior, and increase inter- and trans- disciplinary collaborations" (Barth and Michelsen, 2013). The universities should "integrate education for sustainable development into their curricula in order to enable future professionals to cope with issues of sustainable development in their work" (Rieckman, 2012; Sibble, 2009) and to "reinforce sustainability competencies of students" (Svanstrom et al., 2008; Thomas, 2004). Education for sustainable development implies "culture building, financial aids and research funding". (Noonan and Thomas, 2004). Lately, universities are required to leave their ivory tower and to become more involved in addressing the needs of the society (Paunescu et al, 2017).

According to UNESCO (2017), education for sustainable development relates to the core of teaching and learning, integrating sustainability concepts into the curricula, but also to achieve sustainability-related learning outcomes. In this regard, curricula it is expected to "improve the capacity of our education systems to prepare people to pursue sustainable development" (United Nations, 2012, p 230). An important factor for changes in curriculum and teaching practice is the new approach for a sustainability-centered education (UNESCO, 2014a) and a whole-person approach to educating students (Wu \& Shen, 2016).

According to UNESCO (2017), teachers are the most important drivers for restructuring educational process and moving educational institutions towards sustainability. To ensure the smooth process of EDS, they must develop sustainability key competencies (knowledge, skills, attitudes, values, motivation, and responsibility) through a range of innovative teaching and learning instruments.

Internationalization process is an essential element to facilitate ESD through the use of international debates, based on cultural diversity, providing the opportunity to study abroad, explore practical experiences, participation to UNESCO conferences and specialized 
debates. To have successful outcomes, the participation of key stakeholders such as students, teachers, local NGOs and experts is demanding, having at the same time the appropriate institutional structural conditions and the freedom to engage in organizational learning processes (UNESCO, 2017).

Several authors tried to identify methods for applying sustainability in education. Using a model, Jabbour (2010) analyzed the contribution of business schools to environmental management knowledge; Rusinko (2010) proposed a matrix of options for integrating sustainability in management and business education; Amran et al. (2010) suggested how to promote sustainable development for the business community; Blewitt (2010) discussed the relationship between low-carbon economic development, social sustainability, and higher education learning (Wu \& Shen, 2016).

Developing reliable paths of management education for sustainability is a complex challenge for existing business schools and higher education institutions (Lee and Schaltegger, 2014). The main barriers identified to achieve sustainability are: lack of qualified staff to teach sustainability, lack of resources to develop and implement sustainability instruments, the theoretical and very large character of sustainability (Fishern and Bonn, 2011), lack of leadership, and a lack of accountability mechanisms (Wright, 2002, p. 207).

The current research aims to identify the main directions to implement sustainability in education through curriculum; interdisciplinary/transdisciplinary approach; business environment; entrepreneurship and innovation.

\section{Methodology}

In order to fulfil the main objectives of the present study, a questionnaire-based survey was sent by email to UNESCO Chairs from Balkan Region and the responses were analysed using descriptive statistics and factor analysis.

The questionnaire-based survey had as main purpose the following research objectives:

- The implication of UNESCO Chairs in international projects' implementation;

- The perception over the objectives of the Incheon Declaration and Framework for Action (Education 2030) for the implementation of the Sustainable Development Goal 4 Quality Education;

- The degree of cooperation between UNESCO Chairs in the past;

- The degree of further collaboration in several programmes;

- The main directions implemented for a quality education;

- The relevant directions towards the implementation of sustainability in education through curriculum;

- The principal directions towards the implementation of sustainability in education by an interdisciplinary/ transdisciplinary approach;

- The key directions towards the implementation of sustainability in education through the business environment;

- The main directions in the field of education for entrepreneurship and innovation; 


\section{Results and discussions}

Hypothesis no. 1. The UNESCO Chairs have experience in international projects' implementation. The UNESCO Chairs UNESCO Chairs proved over time that they had a very good collaboration due to the numerous international projects they implemented in partnership. The most important activities, that the UNESCO Chairs were part in, are: Erasmus + projects, Programme Committees, European Commission projects, projects financed by UNESCO, Horizon 2020. (Figure 1)

\section{Figure 1. Relevant programs for UNESCO Chairs}

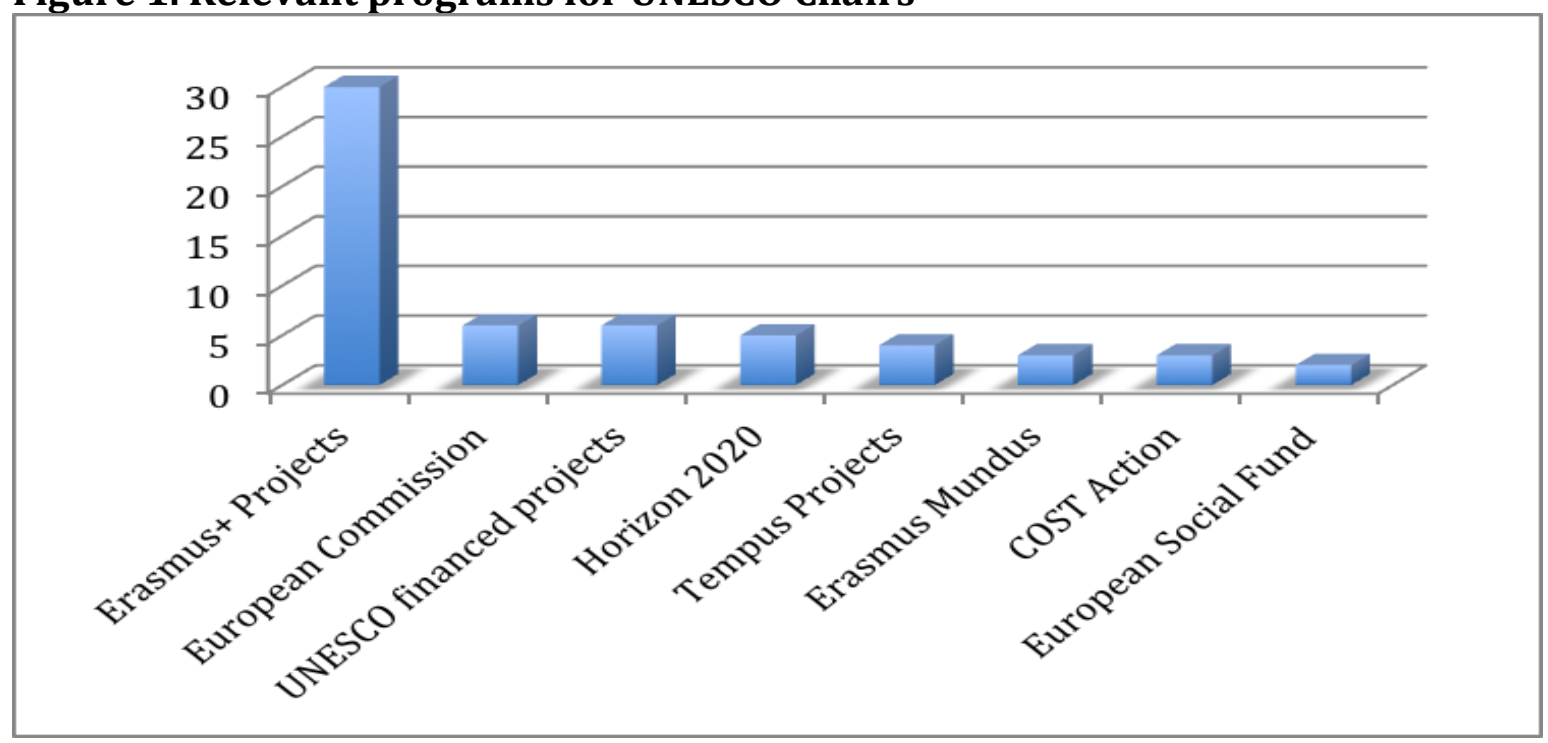

Source: Data analysis based on the received responses.

Hypothesis no. 2. The UNESCO Chairs would prioritize over others, the following objectives of the "Incheon Declaration and Framework for Action (Education 2030)" for the implementation of "Sustainable Development Goal 4 Quality education":

- Item 1: "By 2030, ensure equal access for all women and men to affordable and quality technical, vocational and tertiary education, including university";

- Item 2: "By 2030, substantially increase the number of youth and adults who have relevant skills, including technical and vocational skills, for employment, decent jobs and entrepreneurship";

- Item 3: "By 2030, eliminate gender disparities in education and ensure equal access to all levels of education and vocational training for the vulnerable, including persons with disabilities, indigenous peoples, and children in vulnerable situations";

- Item 4: "By 2030, ensure that all youth and a substantial proportion of adults, both men and women, achieve literacy and numeracy";

- Item 5: "By 2030, ensure that all learners acquire the knowledge and skills needed to promote sustainable development, including, among others, through education for sustainable development and sustainable lifestyles, human rights, gender equality, promotion of a culture of peace and non-violence, global citizenship and 
appreciation of cultural diversity and of culture's contribution to sustainable development";

Using factor analysis as a function for factor reduction, the items that best define the main objectives of the "Incheon Declaration and Framework for Action (Education 2030)" for the implementation of "Sustainable Development Goal 4 Quality education", from the perspective of UNESCO Chairs, are: Item 3, Item 4 and Item 5 . The component matrix indicate that all the chosen items have a structural coefficient $>0,65$. The reliability scale has an acceptable internal coherence. There is not possible to improve the scale by eliminating other items. Thus, we keep this solution with the three items $(3,4,5)$ in order to measure the designed phenomenon. (Table 1)

Table 1. Prioritization of objectives of the "Incheon Declaration and Framework for Action (Education 2030)" for the implementation of "Sustainable Development Goal 4 Quality education"

\begin{tabular}{|l|r|}
\hline \multicolumn{1}{|c|}{ Component Matrix } \\
\hline \multicolumn{1}{|c|}{} & Component \\
\cline { 2 - 2 } & 1 \\
\hline $\begin{array}{l}\text { "By 2030, eliminate gender disparities in education and ensure equal access to all levels of } \\
\text { education and vocational training for the vulnerable, including persons with disabilities, } \\
\text { indigenous peoples, and children in vulnerable situations" }\end{array}$ &, 831 \\
\hline $\begin{array}{l}\text { "By 2030, ensure that all youth and a substantial proportion of adults, both men and women, } \\
\text { achieve literacy and numeracy" }\end{array}$ &, 862 \\
\hline $\begin{array}{l}\text { "By 2030, ensure that all learners acquire the knowledge and skills needed to promote } \\
\text { sustainable development" }\end{array}$ & \\
\hline Extraction Method: Principal Component Analysis. & \\
\hline a. 1 components extracted. & \\
\hline
\end{tabular}

Source: Data analysis based on the received responses with SPSS 20.00 software for Windows.

Hypothesis no. 3. The UNESCO Chairs identified concrete relevant directions to implement sustainability in education through curriculum.

Based on the responses analysis, the relevant directions necessary to implement sustainability in education through curriculum are:

- Cyber security;

- Innovations in education;

- Changes in the curriculum to include new courses relevant to the community needs;

- Incorporation of new technologies for education and involvement of companies and enterprises when developing new courses and curricula;

- Ssustainable Manufacturing;

- Circular Economy;

- Green and Alternative Energy;

- Incorporating topic of sustainability in new courses;

- Develop special courses focused on sustainability;

- Develop study programs in sustainability field; 
- Development of new curricula and joint programmes with other HEIs` UNESCO Chairs or courses/models for diversity and intercultural communication within existing programs;

- Involvement in the Curriculum of all competent, balanced and realistic stakeholders (parents, students, teachers, independent experts, school masters, officers in administration);

- Debates in mass-media;

- Include in the curriculum cycles of feedback / assessment / re-adjustment;

- An exchange about good practices and strategies within and between different schools and disciplines is essential

- Building a capacity of educators in transforming curriculum towards sustainability aim;

- Enable participation of students and faculty members and members from the BBCC (Baltic and Black Sea Consortium) in action research;

- Foster networking and cases of good practice through publication in international Journal;

- Integration of experiential learning as a way of delivering educational programs

In order to promote sustainability and satisfy equality of education at global scale, processes such as the EU Bologna Process could contribute towards this direction. Particularly, apart from the higher education implementation process of Bologna process, similar approaches could be also implemented in lower education levels;

Hypothesis no. 4. The UNESCO Chairs identified concrete relevant directions to implement sustainability in education by an interdisciplinary/transdisciplinary approach.

The relevant directions, necessary to implement sustainability in education by an interdisciplinary approach are:

- Preservation of cultural heritage and digitalization;

- Innovation in education;

- More courses should include students from different majors working in interdisciplinary groups;

- Sustainable Manufacturing;

- Circular Economy;

- Develop interdisciplinary approaches on sustainability;

- Including the sustainability topic in different teaching subjects

- Involve professionals and researchers of different fields, artists included in policy considerations, understanding of issues, ethical dimensions etc.;

- Strengthen the aspects of intercultural communication within the framework of studies so that future professionals in different fields can adopt and apply the values of an inclusive society - a society that integrates diversity.

- Widening the scope of knowledge provided in the different curricula;

- Orienting the knowledge towards the practice;

- Active exchange of students and lecturers among the countries;

- An exchange about good practices and strategies within and between different schools and disciplines is essential; 
- Organizing summer schools, international seminars and international conferences by researchers from the BBCC consortium.

- Providing teachers with competences to switch from insertion of knowledge to integration of knowledge.

Hypothesis no. 5. The UNESCO Chairs identified concrete relevant directions to implement sustainability in education through business environment.

The relevant directions to implement sustainability in education through business environment:

- Entrepreneurship concepts and topics integrated into curricula;

- Digital innovations;

- Development of Innovative Environments;

- Cooperation between the Universities and Business environment;

- Providing internships and scholarships to students who will implement the acquired knowledge about intercultural communications through their engagement in the media and companies;

- Organizing tailor-made workshops and trainings for intercultural communication and diversity reporting for journalists and communications specialists, in cooperation with the media and companies;

- Applied research in the media and communications field;

- Including the perspective of small and medium enterprises in the framework. The sustainability strategies and approaches of small and large companies can vary substantially and their individual context has to be considered;

- Implementing Quadruple Helix concept (business, academia, government, civil society) in designing stimulating and mutually responsible ecosystem for successful education.

Hypothesis no. 6. The UNESCO Chairs identified concrete relevant directions in the field of education for entrepreneurship and innovation.

The relevant directions necessary in the field of education for entrepreneurship and innovation are:

- Cyber security;

- Cultural heritage;

- Collaboration with enterprises to integrate into curricula the needs and expectations of the job market;

- Usage of new technologies in teaching and learning process;

- Development of activities and competencies for Start-ups;

- Development of an Infrastructure for Youth Innovation Entrepreneurship Support;

- Increasing the innovative methods of teaching and learning entrepreneurship and innovation;

- Enable and stimulate students to come and step ahead immediately with fresh idea, and help them design and implement it; 
- Education should ask student to do feasibility study, and adequate contextual preparation, but should not slow down and prevent student idea to be realized just if we do not feel a "need" for that;

- Education for entrepreneurship should be embedded in educational atmosphere, thus the teaching and learning processes should also be entrepreneurial, allowing students to find different modalities of learning / not to use always those foreseen in a curriculum;

- Delivering skills-based training that integrate digital environment in meaningful ways.

- Developing of incubators within HEIs for students` inventions, developments and highquality products;

- Connecting ICTs with traditional educational practices can be an adjuvant tool for fostering education for entrepreneurship and innovation;

- Establishing close links between the Universities and Industry;

- Working with variety of cases and experimenting in the environment;

- Better understanding the "phenomenon" of entrepreneurship and preparing for the psychological barriers for starting business at an early age;

- Improving the status of doing own business versus the employment in a big organization;

- Creating a culture for working in a circular economy;

- Understanding the logic and the methods for feasibility analysis of assets utilization and products/ services design and creation in a circular economy;

- Green and sustainable innovations should be subject of in-class discussion, preferably with hands-on;

- Provide entrepreneurship education across campus (available to all students) and to build it on experiential learning concept.

\section{Conclusions}

In conclusion, the relevant directions to achieve a quality education identified by respondents are:

1. The continuous emergence of the information-communication technologies (ICTs) has put new standards in all human related environments and fields. Thus, the use of these technologies could give access to global information sources and knowledge databases regardless the social background of students/teachers, application of TIC in education, library studies, access to (wisely selected) electronic resources;

2. Practice-based learning includes project-based learning (students create, design, implement and evaluate their own projects), internships, coaching, consulting and problem-solving for NGO sector in the region; develop partnerships between schools, universities and other institutions offering education in different regions of the world; cooperation with business environment.

3. Assessing and evaluating the quality of education are important. Pre and postsurveys of attitudes and skills (and technical skills) of students might be one indicator; since students are ultimately the recipients of education, student 
opinions and demands in education are essential and should be further included as input for curriculum development and as indicator of high quality education with high student satisfaction scores.

4. Developing entrepreneurship and lifelong education programs in order to maintain and improve standards of national and foreign specialists; promoting social responsibility via education to increase good governance and strengthen institutions. However, research-based education requires resources (financial, human, networking).

5. Provide high quality information (Circular Economy, Blue Economy and Blue Growth). Research is seen as action research, linked to public policies, raising capacities of cultural agents and communities in the same time, as giving to students analytical, critical, technical and conceptual skills.

6. Reorienting education towards the aim of sustainable education: publishing open educational resources (e-textbooks, e-manuals, videos and other online materials) in order to advance the theory and enrich the knowledge and sharing of experiences to different society stakeholders - students, professors, HEIs, companies, government institutions (national and local), NGOs; organizing conferences and academic events in order to diseminate results of research

\section{References}

Amran, A., Khalid, S. N. A., Razak, D. A., \& Haron, H. (2010). Development of MBA with specialisation in sustainable development: The experience of Universiti Sains Malaysia. International Journal of Sustainability in Higher Education, 11(3), 260-273.

Barth, M., Michelsen, G. (2013). Learning for change: an educational contribution to sustainability science. Sustain. Sci., 8(1), 103-119.

Blewitt, J. (2010). Higher education for a sustainable world. Education \& Training, 52 (6/7), 477-488.

Bratianu, C. (2010). A critical analysis of Nonaka's model of knowledge dynamics. In Rodrigues, S. (Ed.). Proceedings of the $2^{\text {nd }}$ European Conference on Intellectual Capital, ISCTE Lisbon University Institute, Lisbon, Portugal, 29-30 March 2010 (pp. 115-120). Reading: Academic Conferences and Publishing International.

Bratianu, C. and Bolisani, E. (2015). Knowledge strategy: an integrated approach for managing uncertainty. In Massaro, M. and Garlatti, A. (Eds.). Proceedings of the $16^{\text {th }}$ European Conference on Knowledge Management, University of Udine, Italy, 3-4 September 2015 (pp. 169-177). Reading: Academic Conferences and Publishing International.

Brundiers, K., Wiek, A., Redman, C.L. (2010). Real-world learning opportunities in sustainability: from classroom into real world. International Journal of Sustainability in Higher Education, 11(4), 308-324.

Bryce, P., Johnston, S., Yasukawa, K. (2004). Implementing a program in sustainability for engineers at University of Technology, Sydney: a study of intersecting agendas. International Journal of Sustainability in Higher Education, 5(3), 267-277. 
Bușe, L., Siminică, M., Cîrciumaru, D., Marcu, N. (2007). Analiza economico-financiară a firmei, Sitech.

Chalkley, B. (2006). Education for Sustainable Development: Continuation. Journal of Geography in Higher Education, 30(2), 235-236.

Cristea, M., Dracea, R., Marcu, N. (2010). The direction of the financial sector's involvement in overcoming crisis: A case study of Romania. African Journal of Business

PICBE $\mid 309$ Management, 4(15), 3356.

Dascălu, E. D., Marcu, N., Pete, Ș., Ulici, M. L., Dumitrașcu, V. (2016). Dependent business climate. A network-based analysis. Romanian Journal of Economic Forecasting, 19 (1), 138-152.

Faham, E., Rezvanfar, A., Hamid Movahed Mohammadi, S., Rajabi Nohooji, M. (2016). Using system dynamics to develop education for sustainable development in higher education with emphasis on the sustainability competencies of students. Technological Forecasting \& Social Change, 123, 307-326.

Figueiro, P.S., Raufflet, E., 2015. Sustainability in higher education: a systematic review with focus on management education. Journal of Clean Production, 106, 22-33.

Jabbour, C. J. C. (2010). Greening of business schools: a systemic view. International Journal of Sustainability in Higher Education, 11(1), 49-60.

Lee, K.H. and Schaltegger, S. (2014). Organizational transformation and higher sustainability management education: The case of the MBA Sustainability Management. International Journal of Sustainability in Higher Education, 15(4), 450472.

Lefter, V., Bratianu, C., Agapie, A., Agoston, S. and Orzea, I. (2011). Intergenerational knowledge transfer in the academic environment of knowledge-based economy. Amfiteatru Economic, 13 (30), pp. 307-319.

Noonan, D., Thomas, I. (2004). Greening universities in Australia: progress and possibilities. Aust. J. Environ. Educ., 20(2), 67-79.

Păunescu, C., Drăgan (Gilmeanu), D. and Găucă, O. (2017). Examining obligations to society for QS Stars best ranked universities in social responsibility, Management \& Marketing. Challenges for the Knowledge Society, 12 (4), 551-570. DOI: 10.1515/mmcks-2017-0033.

Rieckmann, M. (2012). Future-oriented higher education: which key competencies should be fostered through university teaching and learning? Futures, 44(2), 127-135.

Sibble, A. (2009). Pathways towards sustainability through higher education. International Journal of Sustainability in Higher Education, 10(1), 68-82.

Rusinko, C. A. (2010). Integrating sustainability in higher education: a generic Matrix.

International Journal of Sustainability in Higher Education, 11(3), 250-259.

Svanstrom, M., Lozano-Garcia, F.J., Rowe, D. (2008). Learning outcomes for sustainable development in higher education. International Journal of Sustainability in Higher Education, 9(3), 339-351.

Thomas, I. (2004). Sustainability in tertiary curricula: what is stopping it happening? Int. J. Sustain. High. Educ., 5(1), 33-47.

UNESCO (2017). Sustainable Development Goal 4 and its targets, https://en.unesco.org/node/265600, accessed at 01.12.2017. 
UNESCO (2015). Education 2030, http://unesdoc.unesco.org/images/0024/002456/245656E.pdf, accessed at 01.12.2017.

UNESCO (2009). Learning for a Sustainable World: Review of Contexts and Structures for Education for Sustainable Development, www.unesco.org/education/justpublished_desd2009.pdf, accessed at 01.12.2017. United Nations (2017). Sustainable Development Goals, https://sustainabledevelopment.un.org/?menu=1300, accessed at 01.12.2017. UNESCO (2017). Education for Sustainable Development Goals. Learning objectives, https://www.developmenteducation.ie/app/uploads/2017/07/Sustainabledevelopment-goals-learning-objectives-2017.pdf

$\mathrm{Wu}$, Yenchun \& Shen, Ju-Peng. (2016). Higher education for sustainable development: a systematic review. International Journal of Sustainability in Higher Education, 17. 633-651. 10.1108/IJSHE-01-2015-0004. 